\title{
INFORMATION SYSTEMS SUPPORTING DISASTER MANAGEMENT OF DROUGHTS
}

\author{
MARIJA TRAUT ${ }^{1}$, ANDREA HOELTL ${ }^{2} \&$ ROMAN BRANDTWEINER ${ }^{1}$ \\ ${ }^{1}$ Vienna University of Economics and Business, Austria \\ ${ }^{2}$ Danube University Krems, Austria
}

\begin{abstract}
In the context of disaster management, drought may seem a relatively harmless natural hazard, but according to the Food and Agricultural Organization (FAO) more than 2 billion people have been affected by drought since 1900 and more than 11 million people died because of it since 1900 . These alarming numbers show quite clearly that information concerning droughts needs to be gathered and analyzed in a structured manner by using advanced technologies, so the effects of droughts can be minimized. Our research has its focus on the usage of information systems in the management of droughts in South Asia. It is designed as desk research. We concentrate on documents released by institutions such as International Water Management Institute and apply the method of document analysis. First, the paper defines disaster management and its different stages, then the natural hazard drought itself, followed by the state of the art of existing information systems. The conclusion provides improvement proposals for the usage of information systems in the field of disaster management.

Keywords: information systems for disaster management, disaster management cycle, drought management, drought indicators, South Asian Drought Monitoring System (SADMS), Global Integrated Drought Monitoring And Prediction System (GIDMaPS).
\end{abstract}

\section{INTRODUCTION}

The Red Cross and the Red Crescent societies define disaster management, as "the organization and management of resources and responsibilities for dealing with all humanitarian aspects of emergencies, in particular preparedness, response and recovery in order to lessen the impact of disasters" [1]. It's a complex set of parallel activities and processes which need to be structured, organized, supervised, continually assessed and improved. Key challenges are linking the different activities to each other in an effective and efficient manner, making sure information is always passed on to the right person or team, raising awareness among the population especially in developing countries and learning from previous events in order to improve the whole process of disaster management. The literature defines the cycle of disaster management consisting of four distinct components: mitigation, preparedness, response, recovery [2]:

1. Mitigation: This phase of disaster management is focused on reducing or eliminating the likelihood or the impact of a hazard, or both.

2. Preparedness: During this phase it's important to assess all possible risks, to develop preparedness plans, train staff, develop awareness among society and implement early-warning systems.

3. Response: Involves activities during a disaster in order to reduce the current impact of it. (Delivering food, provide medical assistance, establishing temporary housing.)

4. Recovery: Returning the victims' lives to a normal stage following the impacts of disaster consequences. This phase usually begins right after the immediate response and can continue for months and years. 


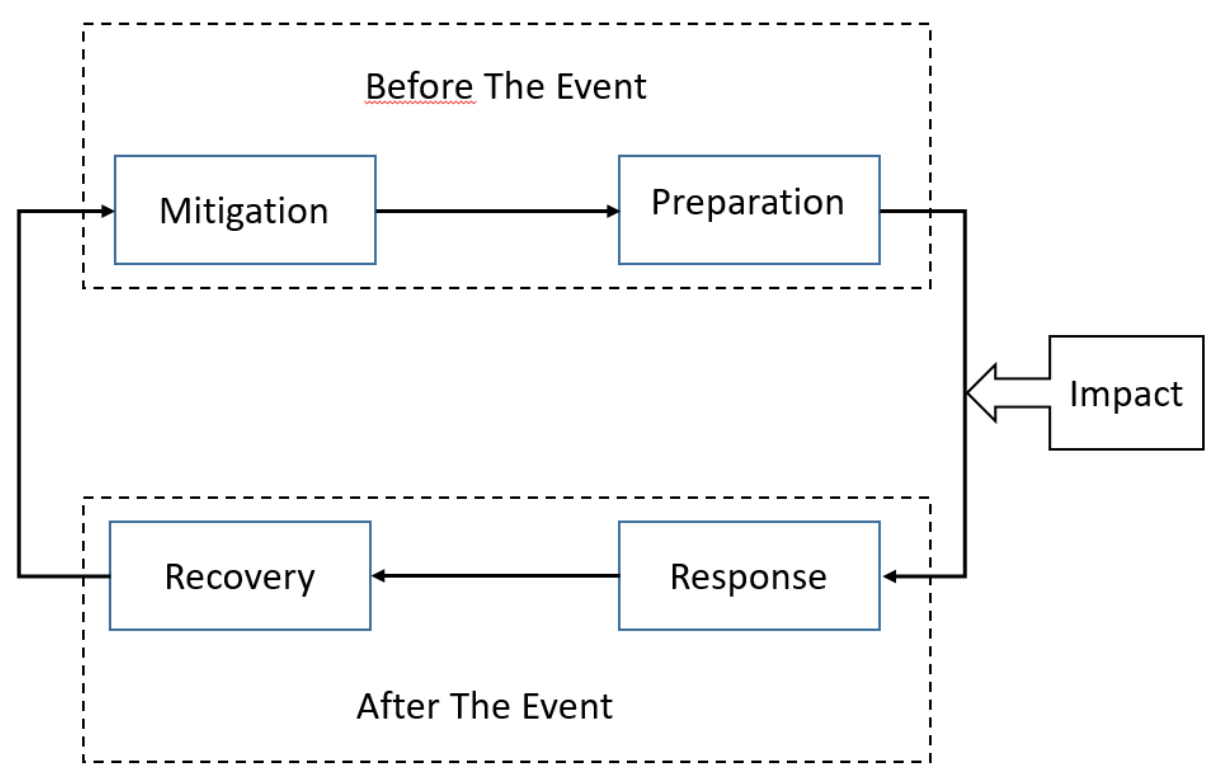

Figure 1: The disaster management cycle [3].

This sure visualizes the different stages of disaster management. This linear model is very popular among institutions and governments for it simplifies the delegation of different tasks [3].

\section{THE NATURAL HAZARD "DROUGHT"}

In the context of disaster management, drought may seem as a relatively harmless natural hazard. By investigating this topic closer it becomes evident that droughts belong to the most devastating natural disasters with the tremendous effects such as loss of harvest, the deaths of livestock, food insecurity for the people resulting in human deaths. According to the Food and Agricultural Organization (FAO) more than 2 billion people have been affected by drought since 1900 and more than 11 million people died because of it since 1900. Moreover, droughts arise more frequently causing widespread human and animal deaths [4].

There is a series of different definitions for drought, focusing on different aspects of the phenomenon. Almost all definitions agree on the fact, that drought is the result of the reduction or absence of precipitation over some period of time, usually a season or more. It's a slow-onset or "creeping" hazard that receives little attention at the beginning, but causes serious problems over time [5]. It differs from other natural hazards since it's very difficult to determine the onset and the end of drought and its impacts are non-structural because they are spread over a much bigger geographical area, compared to other disasters such as floods and hurricanes. Droughts can be distinguished by three essential attributes: intensity, duration and spatial coverage. The intensity is quantified by the degree of the precipitation shortage and by the severity of the impacts of that shortage on society. The duration of drought must be at least two months and can last for years. Droughts also differ from each other in their geographical characteristics because drought-prone areas usually trespass national boarders [6]. Obviously, it's not facile to identify droughts from the beginning on, because many drought-affected regions are usually zones with ongoing high temperatures. It's also difficult to estimate its regional spread and consequences. 
For all these reasons, people are dependent on the usage of information systems for drought assessment and monitoring. Therefore the main research question of the paper is: How do current information systems support the disaster management of droughts?

\section{THE TYPES OF INFORMATION SYSTEMS IN THE MANAGEMENT OF DROUGHTS}

We differentiate between two types of information systems in the management of droughts. First, there are the data collecting technologies, such as satellites equipped with sensors, and second, information systems that process the data and establish through different algorithms the so-called drought indicators. With the help of these indicators, it's possible to give an early warning to the affected people. On these grounds, they are called early-warning systems (EWS). Both of the IS types refer to the stage preparedness. Due to the little attention that droughts have received, in contrast to other hazards like hurricanes, the research for the management of droughts has not been fully developed [5]. There is no all-embracing information system at this moment that is able to capture all activities and to interconnect all involved stakeholders accurately. We focus on the two types of IS that support the processes of the preparedness phase.

\subsection{Sensors}

"A sensor is a mechanical device sensitive to light, temperature, radiation level or the like, that transmits a signal to a measuring or control instrument" [7]. The device in this context is the Moderate Resolution Imaging Spectroradiometer (MODIS) aboard the TERRA and AQUA satellites of the NASA. The two satellites cover the Earth every one to two days, acquiring data in 36 spectral bands or groups of wavelengths, thus creating data bases for research fields like the atmosphere, ocean, land etc. [8]. Some of the 36 spectral bands are relevant for drought assessment [9]. These remote sensing data can be downloaded from the NASA website and utilized for different purposes. MODIS is the fundamental instrument for gathering and aggregating data about our earth system. Sensors might not seem important but MODIS plays an important role in the drought assessment process.

\subsection{Early warning systems}

Early warning $(\mathrm{EW})$ is "the provision of timely and effective information, through identified institutions, that allows individuals exposed to hazard to take action to avoid or reduce their risk and prepare for effective response" [10]. Early warning is based on the idea that the earlier and more accurately risks associated with disasters can be predicted, the more likely the impacts of the disasters on society, economy and environment can be mitigated and managed. Furthermore, it's important that the early warning systems (EWS) are people and location oriented by incorporating the following principles: (1) knowledge of the risks faced; (2) technical monitoring and warning service; (3) dissemination of meaningful warnings to the affected people; and (4) public awareness and preparedness to act [5]. But the natural hazard drought itself has not received that much attention such as other disasters like hurricanes or floods. That's the reason why most countries and governments in drought prone regions apply reactive and crisis-driven approaches [11]. Nevertheless, after hundreds of droughts hitting Asia and the other parts of the world since the midst of the 20th century [12], the governments, international organizations and NPOs are now aware of the importance of EWS. 


\subsection{Drought indicators}

In this section the authors will describe and explain the most common international drought indicators, which are used by the information systems (IS) described later in this paper.

The Standardized Precipitation Index (SPI), developed by McKee et al., is "the" index concerning the measurements of droughts. It measures the observed rainfall as a derivation from a certain probability distribution function (e.g. gamma distribution) that represents the empirical data concerning precipitation over a long period of time. This probability distribution function has to be transformed to a normal distribution and the SPI conforms the standard deviation by which the currently collected data diverges from the long term mean. The drought intensity is reflected in the SPI values. Drought starts as soon as the SPI falls below zero. 0 to -0.99 stands for mild drought whereas -1.0 to -1.49 represents moderate drought and -1.50 to -1.99 already for severe drought. All values below -2.0 stand for extreme drought. Through the SPI a quantitative and functional definition of drought can be created for each period of time. The only requirement for the calculation of the SPI are historic records, which are not always available especially in developing countries [6].

The second indicator we want to introduce is the Normalized Difference Vegetation Index (NDVI). It was first suggested by Tucker in 1979 as an index of vegetation health and density and is the most commonly used vegetation index [13]. For the calculation of the NDVI, you need data from MODIS which is the "primary sensor for monitoring the terrestrial ecosystem in the NASA Earth Observing System (EOS) programme" [14]. The data are radiometric measures of the vegetation constitution and health, profiting from the unique spectral signals of canopy elements, particularly in the red and near-infrared (NIR) portions of the spectrum. The NDVI itself does not reflect drought or non-drought conditions. But the severity of drought or the extent of wetness can be defined as the NDVI deviation from its long-term mean. You can calculate it by measuring the difference between the NDVI for the current point of time (e.g. August 2019) and a long term mean of that month (e.g. the NDVI for all Augusts between 1999-2019). When the deviation is negative it indicates a vegetation condition that is below normal levels and therefore suggests drought conditions. The bigger the negative result the greater the magnitude of the drought [9].

The Vegetation Condition Index (VCI) shows how the NDVI of a current point of time differs to the long term $\mathrm{NDVI}_{\min }$ and was first suggested by Kogan [15]. The long term index is calculated by using the $\mathrm{NDVI}_{\max }$ and the $\mathrm{NDVI}_{\min }$ of a long period of time for a specific month, e.g. the February of 18 years. The values are measured in percent where 50\% means fair vegetation conditions whereas $50-100 \%$ indicates an optimal constitution of the flora. At the VCI value of $100 \%$, the NDVI value of that month is equal to the $\mathrm{NDVI}_{\max }$. Percentages below 50\% represent different stages of drought severity [9], [16].

The Temperature Condition Index (TCI) also recommended by Kogan [15] is calculated similarly to the VCI, except its equation was adjusted in order to display the vegetation's response to temperature (the higher the temperature, the more severe the drought). This index is also displayed in percent, values below the 50\% suggest drought conditions, the lower the value the more extreme the drought. In combination to other indices, the TCI plays a significant role in the prediction of droughts [9].

The Precipitation Condition Index (PCI), is an index based on the data provided by the Tropical Rainfall Measuring Mission (TRMM). The tropical rainfall measuring mission (TRMM) is a cooperation between the NASA and the National Space Development Agency (NASDA) of Japan. The PCI stands for the ratio of (TRMM-TRMM MIN)/(TRMM MAX TRMM $_{\text {MIN }) \text {. TRMM represents a concrete amount of rainfall and TRMM }}$ MIN and TRMM $M_{M A X}$ 
the minimum respectively maximum of it, in same month during a specific period of time e.g. 2009-2019 [17].

The Integrated Drought Severity Index (IDSI) is an integrated indicator used in South Asia and has been developed by the International Water Management Institute [18]. The approach to calculate this index is based on using different remote sensing data (observations of vegetation conditions, climate data and other biophysical information such as land cover/land use type, topography and river basin details) and develop through them individual indicators such as the NDVI, the Vegetation Condition Index (VCI), the Temperature Condition Index (TCI) and the Precipitation Condition Index (PCI). The result of the composition of the former mentioned indicators is the IDSI. The values of the IDSI are then visualized on a map application on the website of the South Asian Drought Monitoring System (SADMS) and can be downloaded and viewed weekly. The description and explanation of the SADMS can be found in the next section [18], [19].

\section{SOUTH ASIAN DROUGHT MONITORING SYSTEMS (SADMS)}

Asia is the biggest continent with the highest population density, being the home of 4.4 billion people. That represents $62 \%$ of the world's population [20]. But the Asian continent is also very vulnerable for all kinds of natural disasters such as tsunamis, floods, cyclones and droughts as well. Asia has suffered a lot from droughts, 345 million people were affected by droughts in the years 2015 and 2016 [21]. The need for efficient drought assessment has never been bigger before.

The South Asian Drought Monitoring System (SADMS) was implemented in 2014 by the International Water Management Institute. It covers the countries Afghanistan, Bangladesh, Bhutan, India, Nepal, Pakistan and Sri Lanka. The system uses remote sensing data, which is derived from sensors such as the Moderate-Resolution Imaging Spectro-Radiometer (MODIS) that are provided from the NASA and other metrics like the Tropical Rainfall Measuring Mission (TRMM), Land Use and Land Cover (LULC), Land Surface Temperature (LST), Globeland and Waterbody Mask [18], [19].

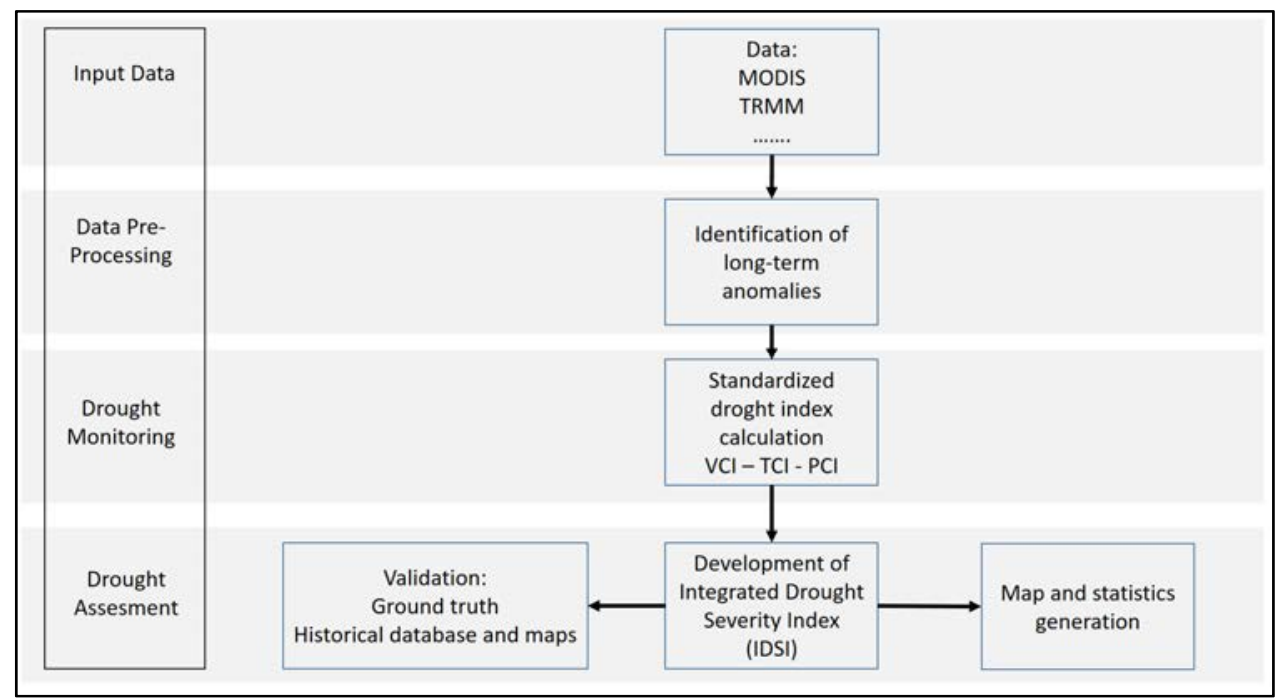

Figure 2: The drought monitoring approach of the South Asian Drought Monitoring System [18], [19]. 
The developed ISDI is being validated with the ground truth values and historical data maps [18], [19]. Ground truth values are physically proven facts, that have been checked locally [22]. In this process the remote sensing images are being compared to the proven facts. After that, it's being integrated on maps of the user application which can be accessed online and statistics are generated too. Through the weekly update of the maps, governments, farmers and the affected people can stay up-to-date and determine actions if needed. The SADMS does not include a specific alerting tool that gives warnings to decision-makers or others. In order to receive a warning, one must access the website and use the application "drought viewer". As the SADMS only replays the current status of drought conditions and does not forecast, we suggest to call it a "real time warning system". The nature of drought is slow and "creeping". Hence there is no requirement for fast, immediate actions. The SADMS visualization makes it easier to gain a better understanding of the drought dimensions and its severity.

\subsection{The application "drought viewer" (User Interface of the Drought Monitoring System)}

The user interface of the viewer is clear to understand, it includes the map with the covering countries (India, Bangladesh etc.), a legend for the drought severity, e.g. dark red stands for extreme drought whereas green means healthy vegetation conditions. The map offers three different layers: (1) the standard precipitation index; (2) an eight-day drought extent; and (3) the monthly drought extent. The two latter are understandable due to the drought severity legend. The SPI is not explained and has no legend, but based on logical thinking one can assume, that areas marked dark blue, are areas with strong rainfalls to this current point of time. In contrast to those, are the yellow/red marked areas, which represent regions with currently little or scarce precipitation.

The integrated player in the application allows it to replay past years by choosing different time intervals, although it only begins from 2001. Other tools like zoom in and out and the appearance/disappearance of the legend are incorporated too. The discussion of the SADMS will follow after the introduction of another drought monitoring system that will be presented in the next part.

\section{GLOBAL INTEGRATED DROUGHT MONITORING AND PREDICTION SYSTEM}

The Global Integrated Drought Monitoring And Prediction System (GIDMaPS ) has been developed in the USA, another large country with numerous drought-prone regions. The GIDMaPS provides information about meteorological and agricultural drought conditions, based on numerous satellite- and model-based precipitation and soil moisture data sets. It includes a near-real time drought monitoring element as well as a seasonal prediction tool. The aggregated data sets contain past drought severity information from the monitoring tool and presumable seasonal forecasts. In contrast to the SADMS, the forecasts of GIDMaPS are probabilistic, thus delivering fundamental information for early warning, protective operations and mitigation strategies [23]. Both provide drought information based on several drought indicators.

\subsection{Methods}

The GIDMaPS applies a similar algorithm calculation as the SADMS using remote sensing data from the Modern-Era Retrospective analysis for Research and Applications 
(MERRALand), the North American Land Data Assimilation System (NLDAS), the Global Land Data Assimilation System (GLDAS) and the Global Drought Climate Data Record (GDCDR). The results generated by the algorithm are the following three indicators: The Standardized Precipitation Index (SPI), the Standardized Soil Moisture Index (SSI) and the Multivariate Standardized Drought Index (MSDI) [23], [24]. The SPI and the SSI refer to meteorological and agricultural droughts and are acquired through a nonparametric method [25]. The probabilities of soil moisture and precipitation are computed based on empirical data.

As you can see in Fig. 3, there is a monitoring component as well as a prediction component which is based on the theory of the Ensemble Streamflow Prediction (ESP) method that has been the foundation for several other hydrological and climate studies. The concept of this method suggests that historical data can represent probable future conditions. The prediction component broadens the duration-based drought prediction to a multi-index scheme by integrating different variables, thus providing short-time forecasts for the univariate (SPI, SSI) and the multivariate index (MSDI) [23], [24].

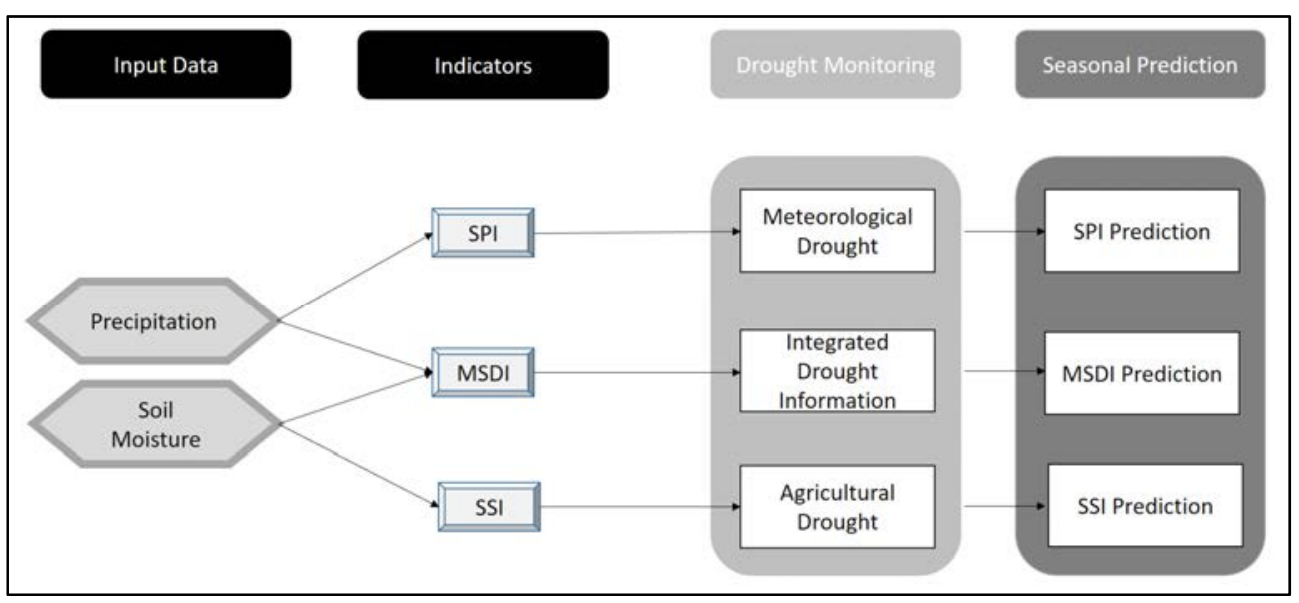

Figure 3: The schematic view of the GIDMaPS' algorithm (SPI, SSI and MSDI) [23].

\subsection{The application of GIDMaPS/user interface}

Unlike the SADMS, the GIDMaPS covers the entire globe and shows dry and wet conditions at the same time. You can choose between the three indicators and between drought monitoring as well as the predictions. The legend is explained below the user interface. At this moment, one can find the application on a sub-website of the University of California, Irvine (UCI) [23]-[25]. But, as it seems, the GIDMaPS is currently not operating.

\section{ANALYSIS OF THE SADMS AND THE GIDMAPS}

The information systems SADMS and GIDMaPS are both sophisticated instruments for the assessment of drought conditions. The two rely on remote sensing data from which they derive their chosen drought indicators. The calculation of those is based on algorithms that generally compare historical data of factors such as precipitation, with current measures of that factor. Furthermore, one and the other have developed integrated drought indices, the SADMS the Integrated Drought Severity Index (IDSI), the GIDMaPS the Multivariate 
Drought Severity Index (MDSI). These indices are the results of the composition of the other indices (SPI, TCI, VCI; SPI, SSI). In contrast to the SADMS, the developers of the GIDMaPS claim to have included a prediction tool. The authors were not able to verify how far the prediction tool works, because it has not been updated since May 2016. The calculation of the forecasts was not fully replicable due to lack of information. However, the approach to implement a risk variable seems to be reasonable and more advanced, compared to the SADMS. After the establishment of the drought indicators, they are integrated and visualized on maps, so affected people and decision-makers are able to see and catch the extent of the droughts. Both tools of both systems are comprehensible and self-explaining, so local people like farmers, can access them online and monitor their region comfortably. The monitoring application is a big advancement for the developing countries in the management of droughts in South Asia. Farmers can extract data from the tool and turn to the government for help. The application makes droughts tangible for the locals as well as for the authorities. Although the SADMS has not a distinct early warning component, the real-time warning is already a progress and sufficient for reactive measures. It is needless to say, that the two scrutinized information systems only cover the stage of preparedness in the cycle of disaster management. But due to the complex nature of droughts, research heavily focused on the assessment process, which is why the other phases of disaster management have been neglected more or less.

\section{RESULTS}

At the beginning of our drought related studies, the authors had the ideal of a holistic information system that interconnects all stages in the management of droughts. However, the results of our research revealed that information systems like the SADMS in South Asia, support the disaster management of droughts in the assessment of droughts and in drought monitoring. These processes are crucial for the management of droughts since drought assessment is such a complicated task which cannot be accomplished without the help of information technologies. The development of a reliable drought assessment instrument is a challenging assignment, which is why research heavily concentrated on this part of disaster management.

\section{CONCLUSIONS}

Droughts are still the least understood of all natural hazards [11], causing significant water deficits, economic losses and food insecurity [9]. Even though it has received less attention than other natural hazards like earthquakes or hurricanes, functional drought assessment methods have been developed all over the globe, setting a milestone for further research and development potential. The recommendations of the authors for the SADMS are, the integration of a prediction/forecasting component that also considers the factor risk similarly to the GIDMaPS. Furthermore, we recommend to implement an alerting/communicating unit, that sends automatic notifications to authorities and decision-makers, e.g. a specific region in Pakistan is suffering due to very high temperatures and no rain for the last three months. The alerting unit, recognizes the current problem and notifies the regional government of that affected area by sending emails to assigned persons whose email addresses are deposited in the SADMS. An analysing instrument must be established and integrated in order to achieve this goal. But the alerting tool won't solve the problem of droughts, of course. Many drought researchers criticize the fact that governments operate responsively rather than preventively. For the effective management of droughts, it's important that governments and authorities develop a plan what to do when a drought strikes, assign and train staff for the emergency case, raise funds for droughts and implement profound strategies for the efficient mitigation 
of future events. It's substantial that all activities and processes of disaster management have been carefully considered, process owners assigned and resources made available.

\section{REFERENCES}

[1] International Red Cross and Red Crescent, National Societies about disaster management. www.ifrc.org/en/what-we-do/disaster-management/about-disastermanagement/. Accessed on: 22 May 2017.

[2] Coppola, D.P., Introduction to International Disaster Management, Elsevier/Butterworth-Heinemann: Amsterdam, Boston, Heidelberg, London, New York, Oxford, Paris, San Diego, San Francisco, Singapore, Sydney, Tokyo, 2006.

[3] Wilhite, D., Sivakumar, S.V.D. \& Wood, D.A., Early Warning Systems for Drought Preparedness, World Meteorological Organization, 2000.

[4] Food and Agricultural Organization (FAO), About droughts. www.fao.org/emergencies/emergency-types/drought/en/. Accessed on: 20 May 2017.

[5] Grasso, V.F., Early Warning Systems: State-of-Art Analysis and Future Directions, United Nations, 2012.

[6] McKee, T.D., Doesken, N.J. \& Kleist, J., The relationship of drought frequency and duration to time scales. Eighth Conference on Applied Climatology, Anaheim, California, 1993.

[7] www.dictionary.com/browse/sensor. Accessed on: 20 Jun. 2017.

[8] NASA, The Moderate Resolution Imaging Spectroradiometor (MODIS). https://modis.gsfc.nasa.gov/about/. Accessed on: 29 May 2017.

[9] Thenkabail, P., Gamage, M. \& Smakhtin, V., The Use of Remote Sensing Data for Drought Assessment and Monitoring in Southwest Asia, 1st ed., International Water Management Institute: Colombo, Sri Lanka, 2004.

[10] UNISDR, Terminology: Basic terms of disaster risk reduction, 2006. www.unisdr.org/files/7817_7819isdrterminology11.pdf. Accessed on: 29 May 2017.

[11] Pulwarty, R.S. \& Sivakumar, M.N.V., Information systems in a changing climate: Early warnings and drought risk management. Weather and Climate Extremes, 3, pp. 14-21, 2014.

[12] Spinoni, J. et al., A new global database of meteorological drought events from 1951 to 2016. Journal of Hydrology: Regional Studies, 22(2019), 100593.

[13] Jensen, J.R., Introductory Digital Image Processing: A Remote Sensing Perspective, Prentice Hall: Saddle River, NJ, 1996.

[14] Justice, C.O. et al., The MODIS fire products. Remote Sensing Environments, 83(12), pp. 244-262, 2002.

[15] Kogan, F.N., Application of vegetation index and brightness temperature for drought detection. Advances in Space Research, 15(11), pp. 91-100, 1995.

[16] Jiao, W., Zhang, L., Chang, Q., Fu, D., Cen, Y. \& Tong, Q., Evaluating an enhanced Vegetation Condition Index (VCI) based on VIUPD for drought monitoring in the Continental United States. Remote Sens., 224, 2016.

www.researchgate.net/publication/297754967_Evaluating_an_Enhanced_Vegetation _Condition_Index_VCI_Based_on_VIUPD_for_Drought_Monitoring_in_the_Contin ental_United_States. Accessed on: 19 May 2019.

[17] Du, L. et al., A comprehensive drought monitoring method integrating MODIS and TRMM data. International Journal of Applied Earth Observation and Geoinformation, 23(2013), pp. 245-253, 2013.

[18] International Water Management Institute, The South Asian Drought Monitoring System, 2014. http://dms.iwmi.org/index.php. Accessed on: 29 May 2017. 
[19] SADMS Drought Monitoring System. http://dms.iwmi.org/app/. Accessed on: 29 May 2017.

[20] World Atlas, www.worldatlas.com/webimage/countrys/as.htm. Accessed on: 19 May 2019.

[21] Guha-Sapir, D., Hoyois, P., Wallemacq, P. \& Below, R., Annual Disaster Statistical Review 2016: The Numbers and Trends, 2016. https://reliefweb.int/report/world/ annual-disaster-statistical-review-2016-numbers-and-trends. Accessed on: 19 May 2019.

[22] www.dictionary.com/browse/ground-truth. Accessed on: 21 Jun. 2017.

[23] Hao, Z., AghaKouchak, A., Nakhjiri, N. \& Farahmand, F., Global integrated drought monitoring system. Scientific Data 1, 140001, 2014. www.nature.com/articles/sdata20141.pdf.

[24] GIDMaPS Drought Viewer, http://drought.eng.uci.edu/. Accessed on: 29 May 2017.

[25] Hao, Z. \& Agha Kouchak, A., Multivariate standardized drought index: A parametric multi-index model. Adv. Water Resour., 57, pp. 12-18, 2013. 